\title{
Synthesis and Biological Activity of Photopolymerizable Derivatives of Glyphosate
}

Aneta Bogdanova, Victoria Piunova, Daniel Berger ${ }^{¥}$, Andrei V. Fedorov ${ }^{\dagger *}$ Douglas C. Neckers*

Center for Photochemical Sciences", Bowling Green State University, Bowling Green, OH 43403

\author{
neckers@photo.bgsu.edu \\ ${ }^{¥}$ Permanent Address: Science Department, Bluffton College, Bluffton, OH 45817 \\ ${ }^{\dagger}$ Wright Photoscience Laboratory, Bowling Green State University, Bowling Green, OH \\ 43403 \\ avfedor@bgnet.bgsu.edu
}

\section{Supporting Information}




\section{Additional NMR Spectra}

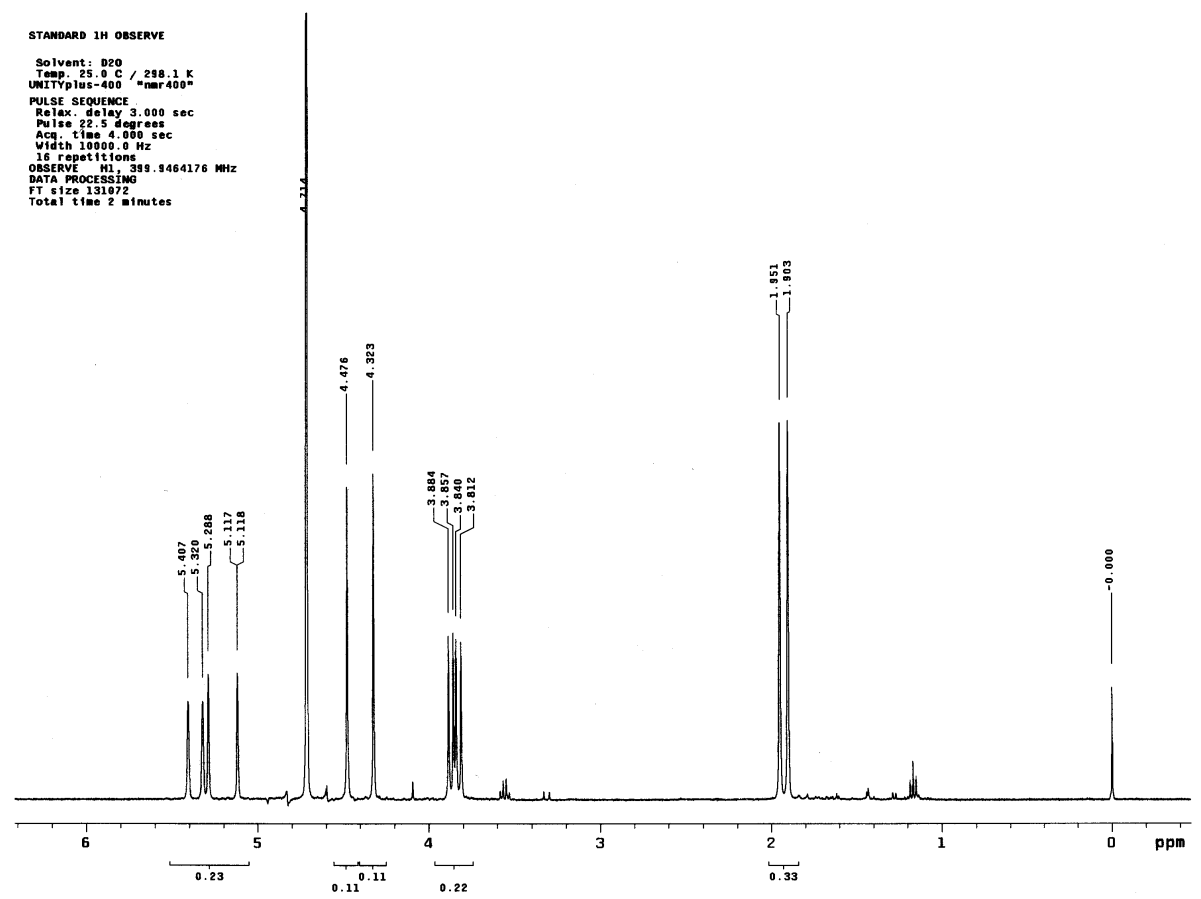

Figure S1. ${ }^{1} \mathrm{H}$ NMR spectrum of MA.

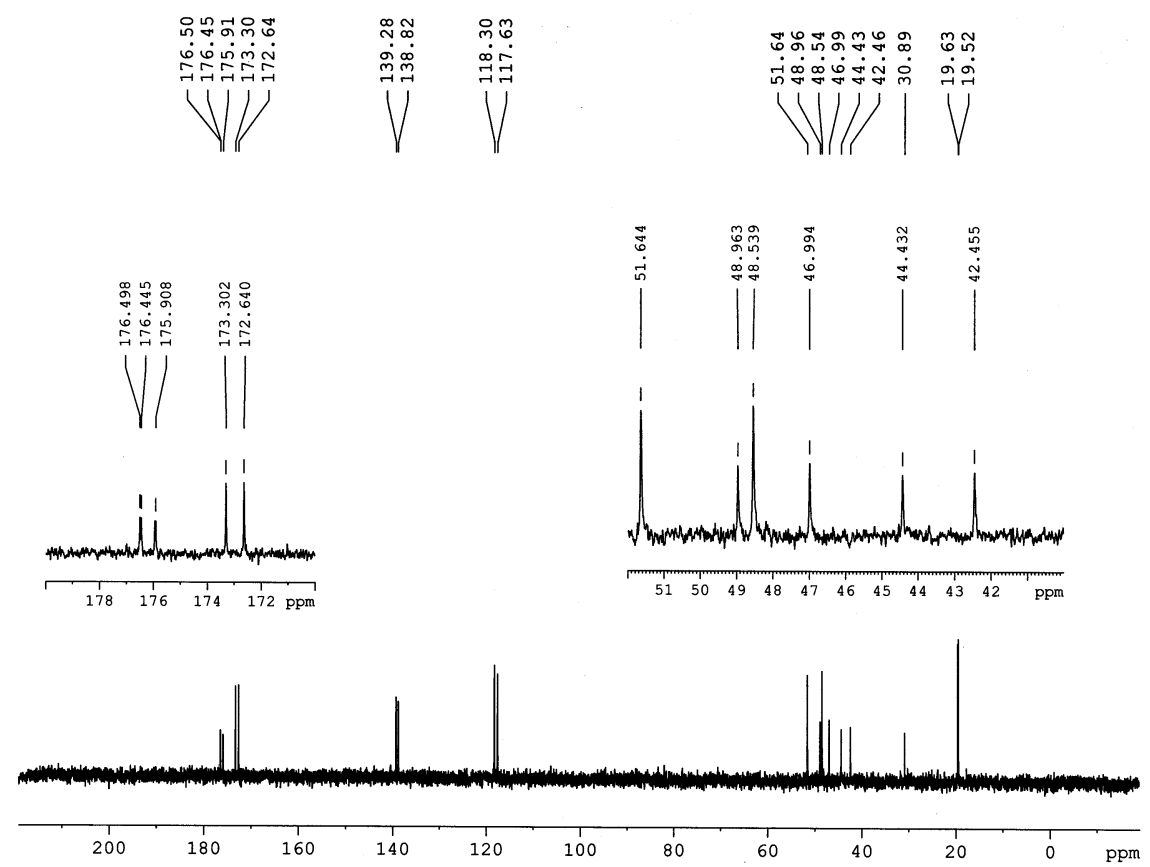

Figure S2. ${ }^{13} \mathrm{C}$ NMR spectrum of MA. 


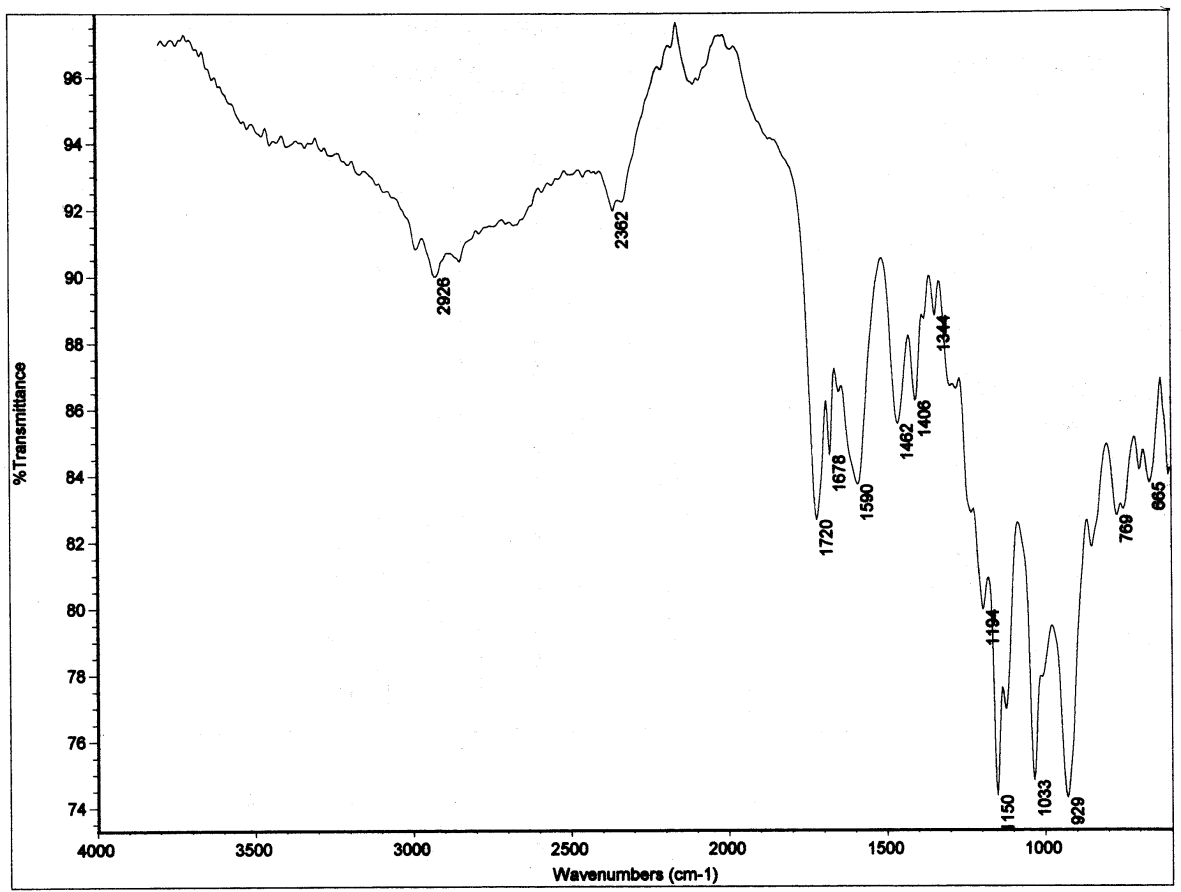

Figure S3. FTIR spectrum of neat MA.

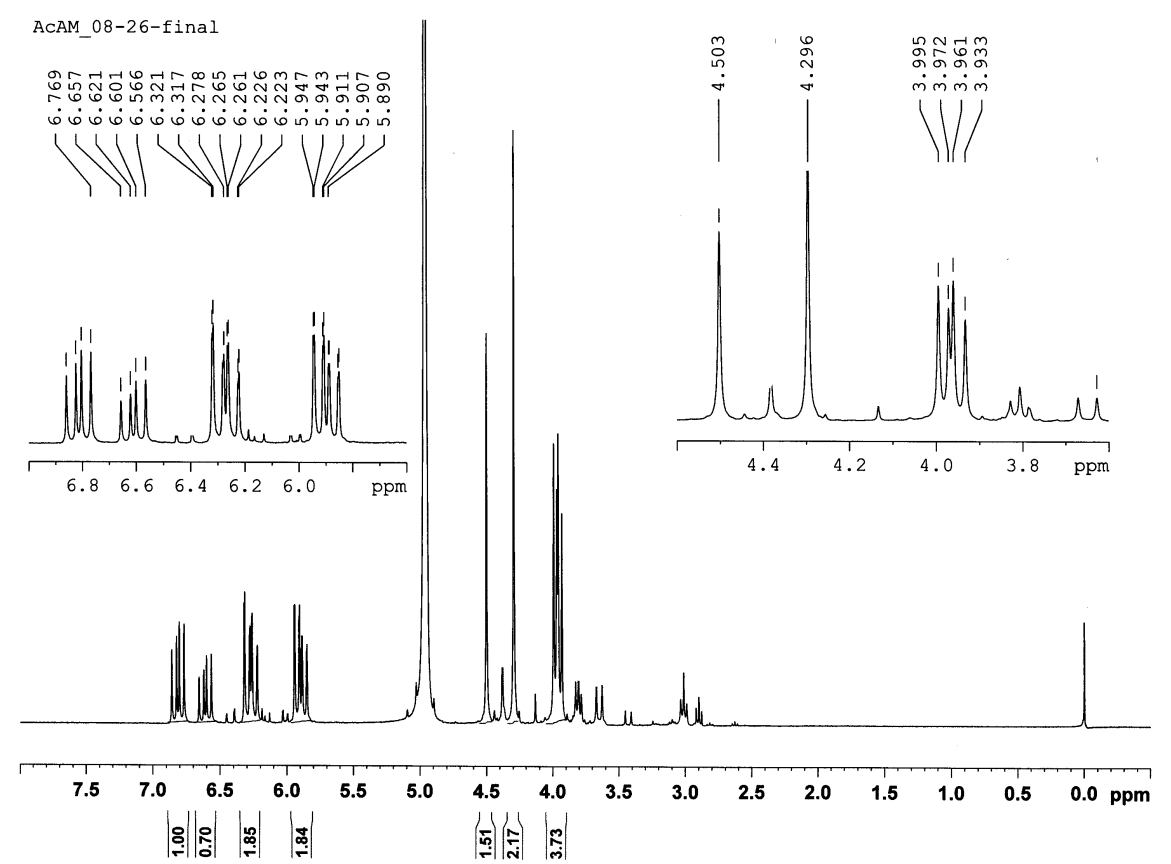

Figure S4. ${ }^{1} \mathrm{H}$ NMR spectrum of AA. 

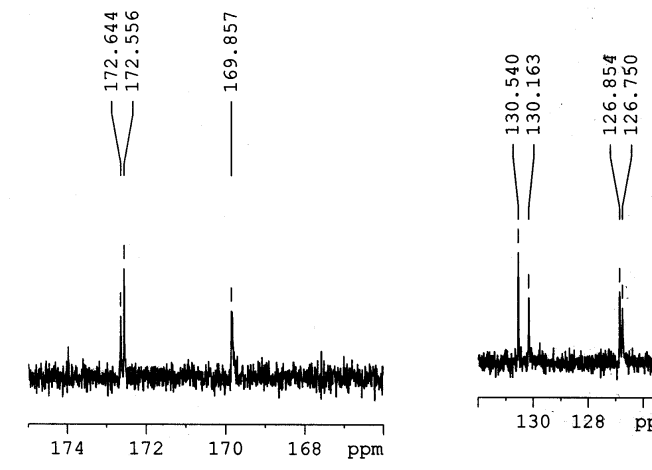

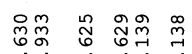

ப்
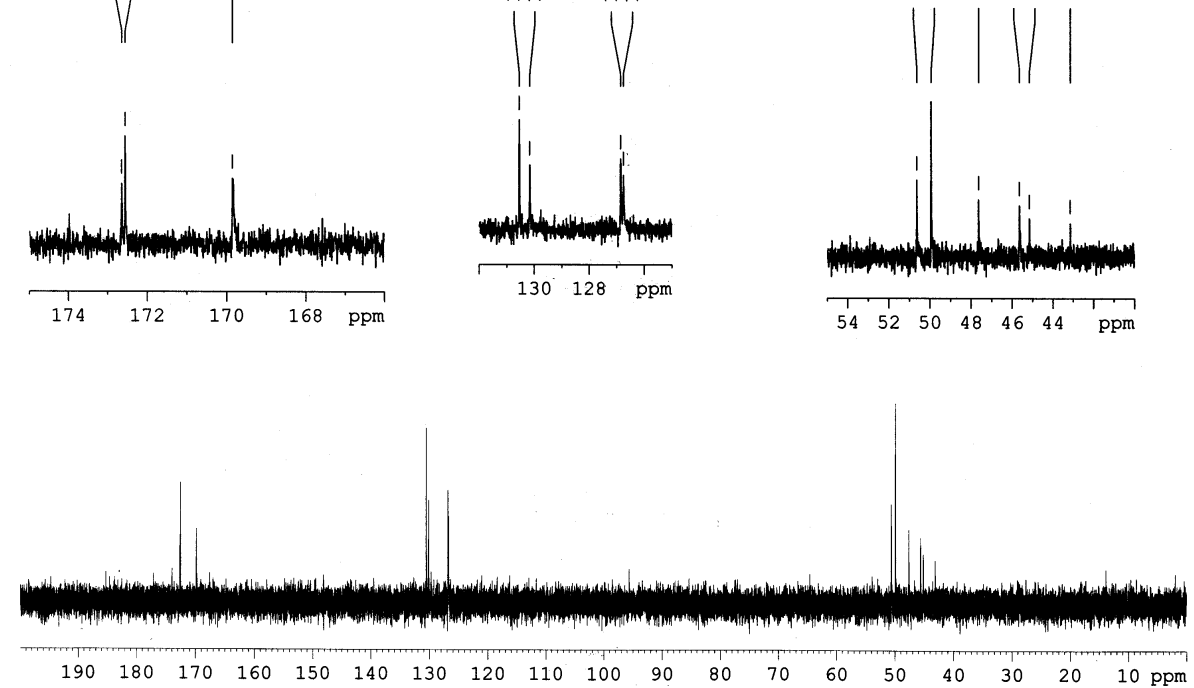

Figure S5. ${ }^{13} \mathrm{C}$ NMR spectrum of AA.

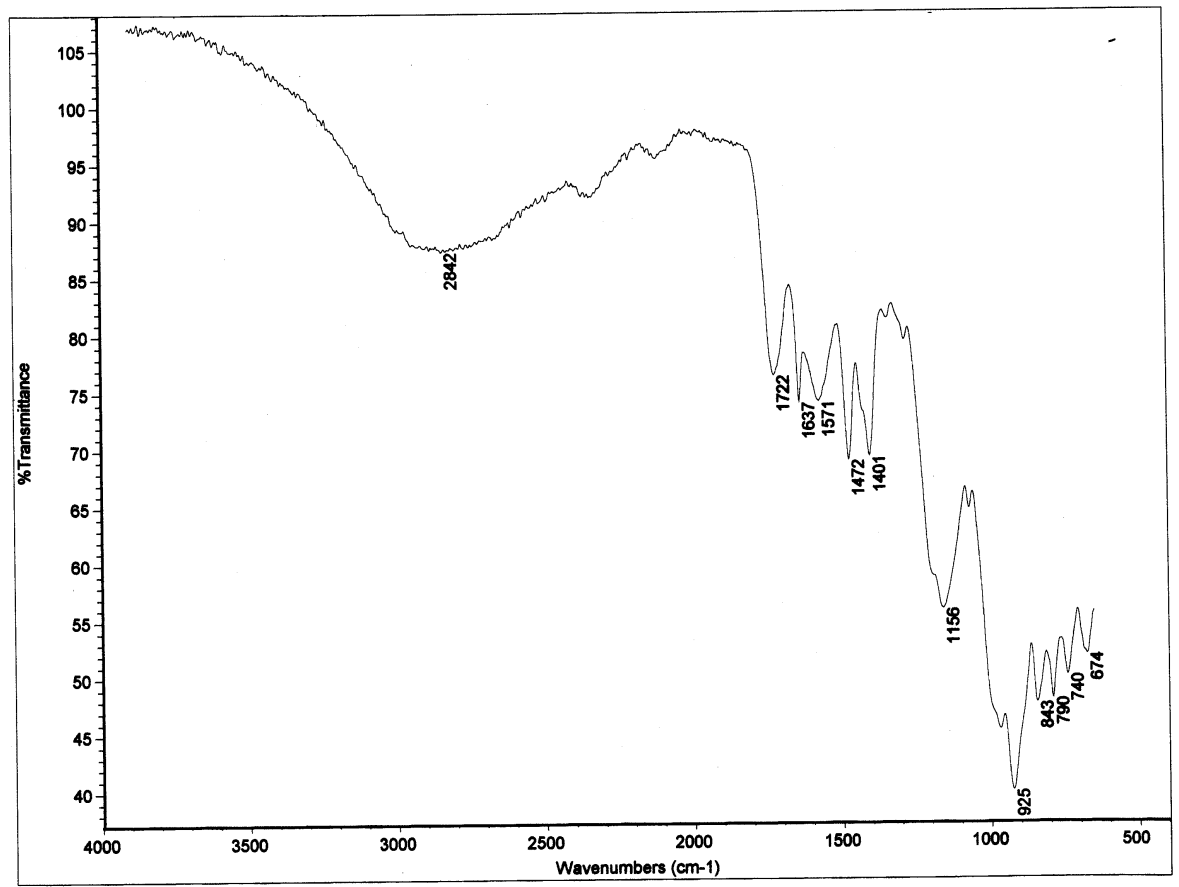

Figure S6. FTIR spectrum of neat AA. 


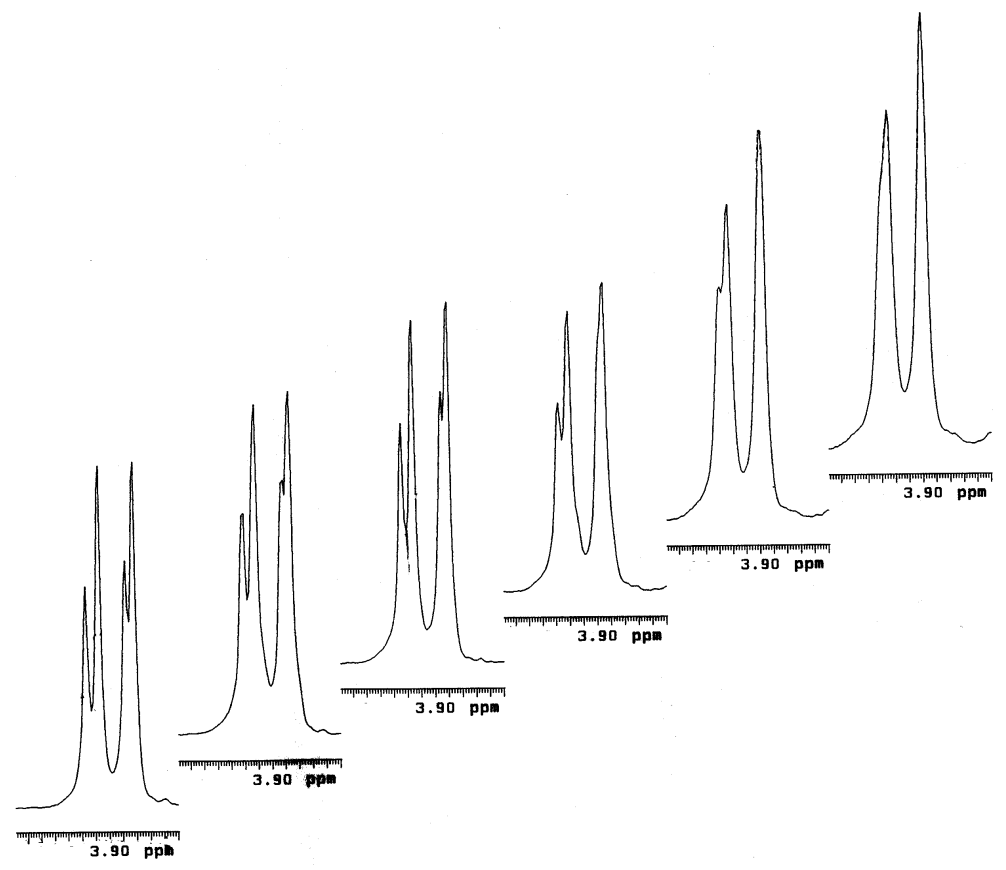

Figure S7. Temperature-dependent 1H NMR spectrum of AA.

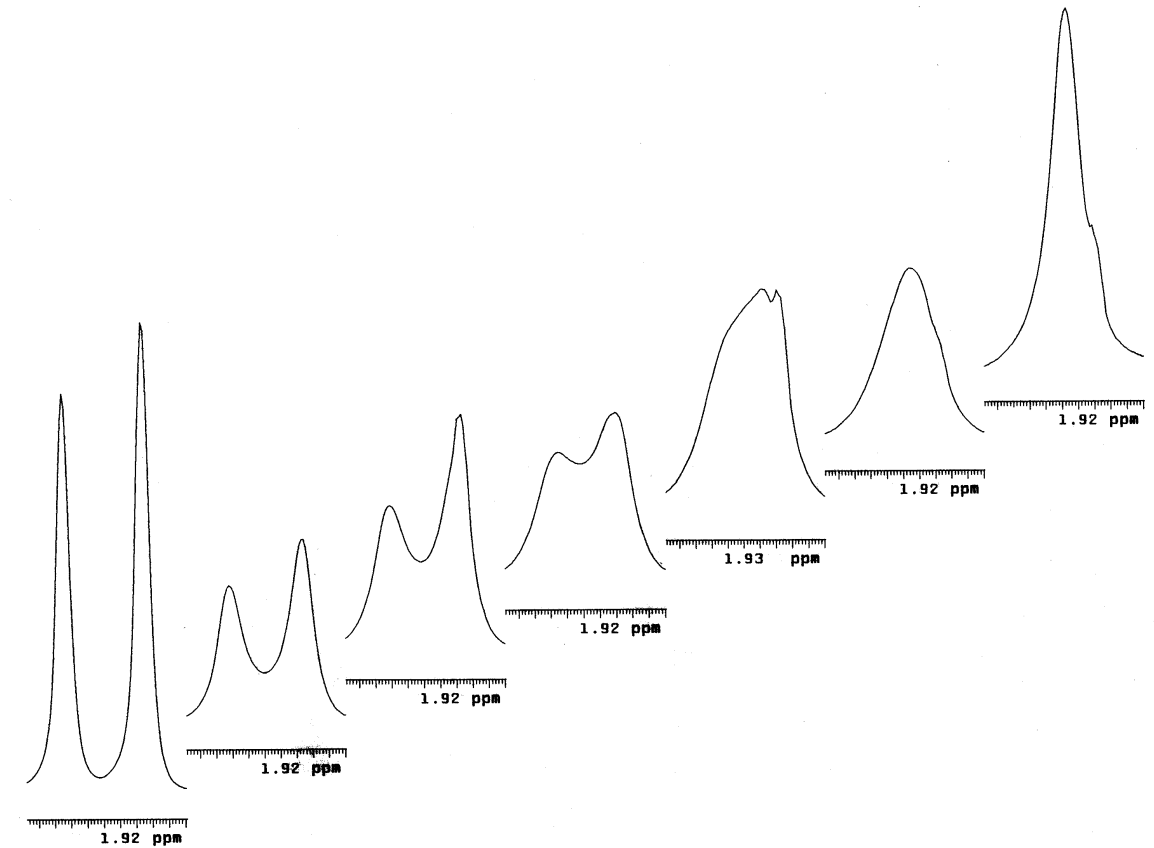

Figure S8. Temperature-dependent 1H NMR spectrum of MA. 


\section{Additional Details of Calculations}

The compounds analyzed were N-acryloyl-N-phosphonomethylglycine (AA) and Nmethacryloyl-N-phosphonomethylglycine (MA).<smiles>C=C(C)C(=O)N(CC(=O)O)CP(=O)(O)O</smiles>

AA<smiles>C=C(C)C(=O)N(CC(=O)O)CP(=O)(O)O</smiles>

MA

Structures were chosen to maximize hydrogen bonding. Some structures were chosen in which the phosphoryl group was a hydrogen-bond donor to the acryloyl carbonyl, while the carboxyl group was a hydrogen-bond donor to the negative phosphoryl oxygen. Other structures were chosen with the carboxyl group as a hydrogen-bond donor to the acryloyl carbonyl, while the phosphoryl group was a hydrogen-bond donor to the carboxyl group. Calculations were performed using Spartan ' $04,{ }^{1}$ except for B3LYP/6-31++G(d,p) calculations which were performed using Gaussian '03. ${ }^{2} \mathrm{PM} 3$ semi-empirical calculations and density functional methods with diffuse basis sets were used in order to keep the structures from losing their hydrogen-bonded character during optimization. Rotational studies were performed, in which one of two chosen dihedral angles was constrained to a series of values and the rest of the molecule was allowed to relax. Several series of structures were generated by constraining a certain dihedral angleeither the acryloyl $\mathrm{C}=\mathrm{C}-\mathrm{C}=\mathrm{O}$ dihedral $(1-2-3-4)$ or the amide $\mathrm{C}(\mathrm{P})-\mathrm{N}-\mathrm{C}=\mathrm{O}$ dihedral (a-b$\mathrm{c}-\mathrm{d}$ ) - and allowing the rest of the structure to relax by sequential molecular mechanics, PM3 and B3LYP/6-31G calculations.

MA. Structural series were generated by rotating the vinyl group of the methacryloyl moiety, with hydrogen-bond donation to the methacryloyl carbonyl from either the phosphoryl group or the carboxyl group. Possible local minima were identified at ca. $135^{\circ}$ and ca. $240^{\circ}$ for both series, with the dihedral angle defined as $\mathrm{C}=\mathrm{C}-\mathrm{C}=\mathrm{O}(1-2-3-4)$.

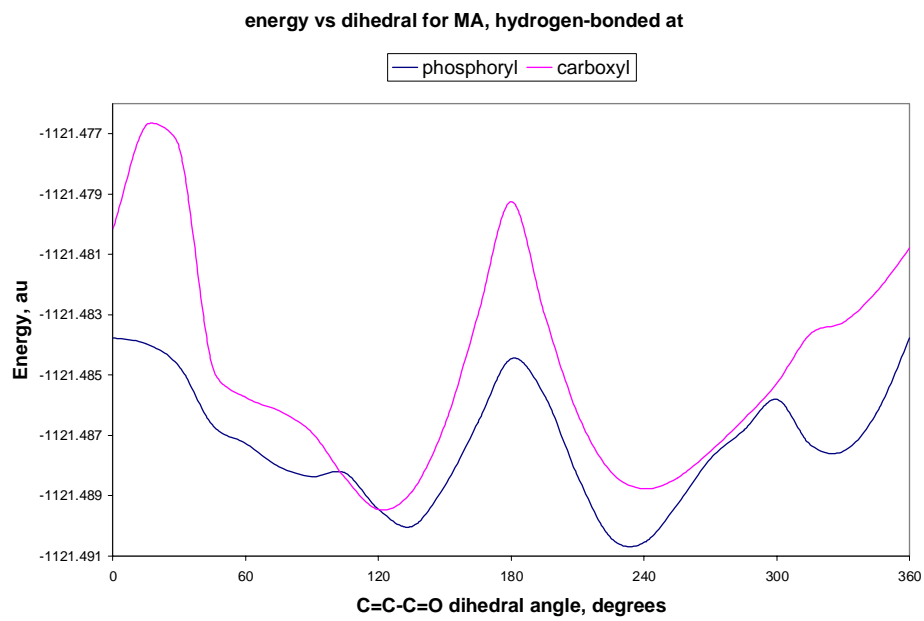

Only one series was generated for rotation of the amide C-N bond, since whether the methacryloyl carbonyl can accept hydrogen bonds from the phosphoryl or the carboxyl 
group will depend on the value of the dihedral angle. Possible local minima were identified for dihedral angles of ca. $0^{\circ}$ and ca. $180^{\circ}$, with the dihedral angle defined as $\mathrm{C}(\mathrm{P})-\mathrm{N}-\mathrm{C}=\mathrm{O}(\mathrm{a}-\mathrm{b}-\mathrm{c}-\mathrm{d})$.

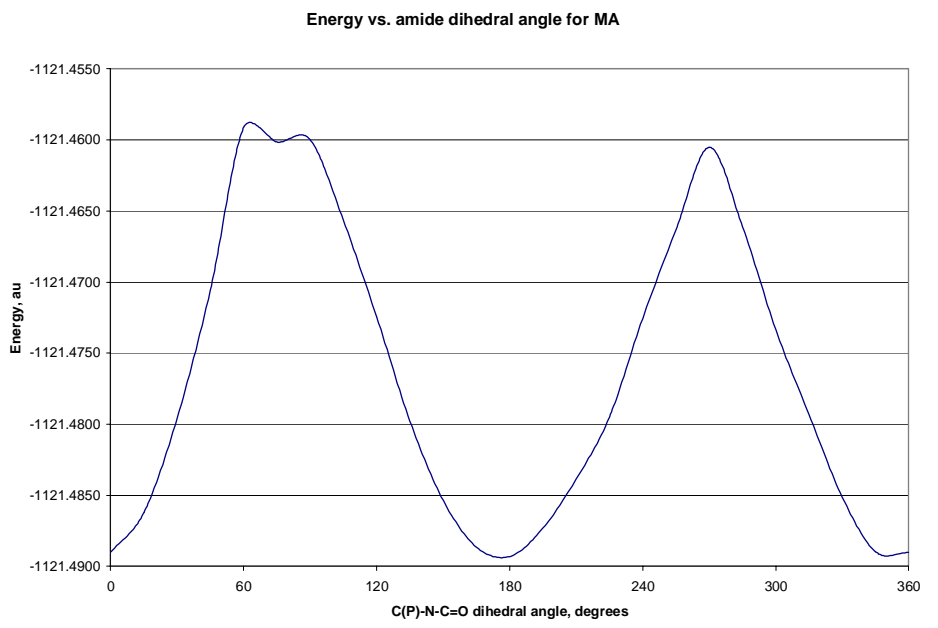

AA. Structural series were generated by rotating the vinyl group of the acryloyl moiety, with hydrogen-bond donation to the acryloyl carbonyl from either the phosphoryl group or the carboxyl group. Possible local minima were identified at ca. $0^{\circ}$, ca. $135^{\circ}$ and ca. $240^{\circ}$ for both series, with the dihedral angle defined as $\mathrm{C}=\mathrm{C}-\mathrm{C}=\mathrm{O}(1-2-3-4)$. Another possible local minimum was identified at $60^{\circ}$ for the series in which the carboxyl group served as the hydrogen-bond donor to the acryloyl carbonyl.

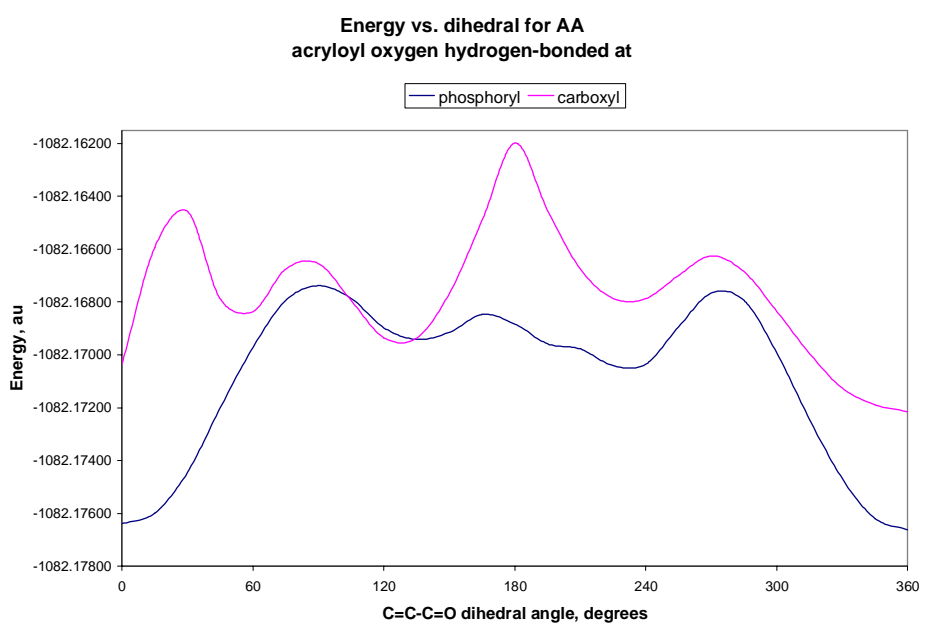

Only one series was generated for rotation of of the amide $\mathrm{C}-\mathrm{N}$ bond, since whether the acryloyl carbonyl can accept hydrogen bonds from the phosphoryl or the carboxyl group will depend on the value of the dihedral angle. Possible local minima were identified for dihedral angles of ca. $0^{\circ}$ and ca. $180^{\circ}$, with the dihedral angle defined as $\mathrm{C}(\mathrm{P})-\mathrm{N}-\mathrm{C}=\mathrm{O}$ (ab-c-d). 


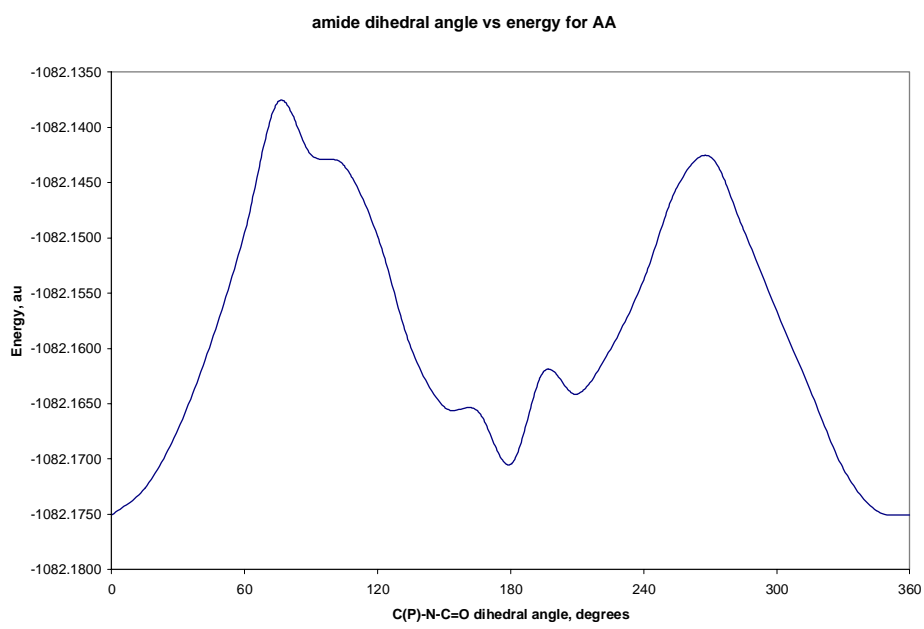

Initial choice of local minima. Geometries at and near the local minima identified by the rotational studies were fully optimized (no dihedral angle constraints) at the B3LYP/6$31+\mathrm{G}^{*}$ level.

MA. Eight candidate local minima were found, grouped at vinyl dihedral angles of \pm 120 $130^{\circ}$ and $\pm 40-60^{\circ}$. Amide dihedral angles were all within $15^{\circ}$ of planarity.

AA. Nine candidate local minima were found, grouped at vinyl dihedral angles from $-6^{\circ}$ to $+8^{\circ}$; from $+127^{\circ}$ to $+132^{\circ}$; and from $-126^{\circ}$ to $-132^{\circ}$.

Identification of relevent local minima. Candidate local minima were fully optimized at the B3LYP/6-31++G(d,p) level using Gaussian '03. Vibrational analysis confirmed that all structures found were indeed local minima.

MA. All identified local minima had methacryloyl dihedral angles (1-2-3-4) of roughly $\pm 120^{\circ}$ and energies within $2.5 \mathrm{kcal} / \mathrm{mol}$ of each other. The two lowest-energy minima found had calculated energies within $200 \mathrm{cal}$ of each other and methacryloyl dihedral angles of $-123^{\circ}$ and $+121^{\circ}$. The structure of the "global" minimum is shown here:

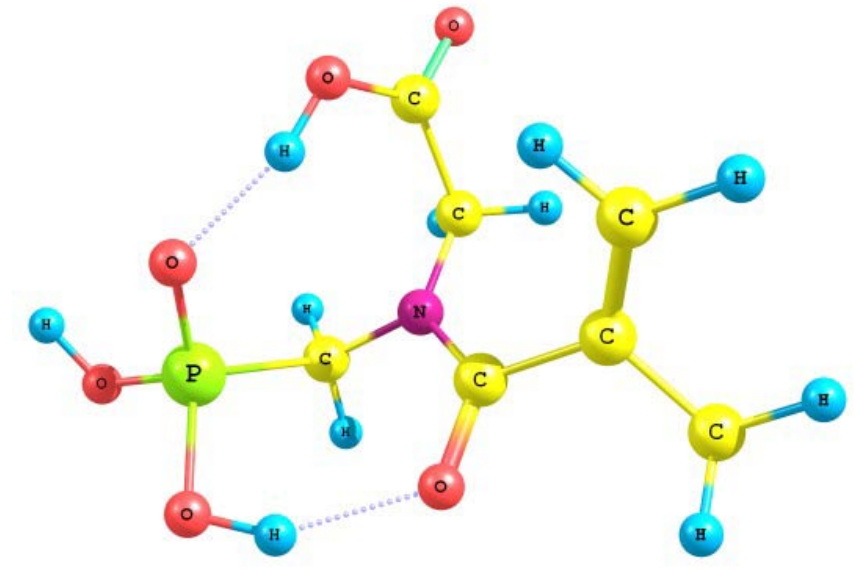

Structures with the carboxyl group as hydrogen-bond donor to the methacryloyl carbonyl oxygen had energies about $2 \mathrm{kcal} / \mathrm{mol}$ above the global minimum. A representative structure of this type is shown: 


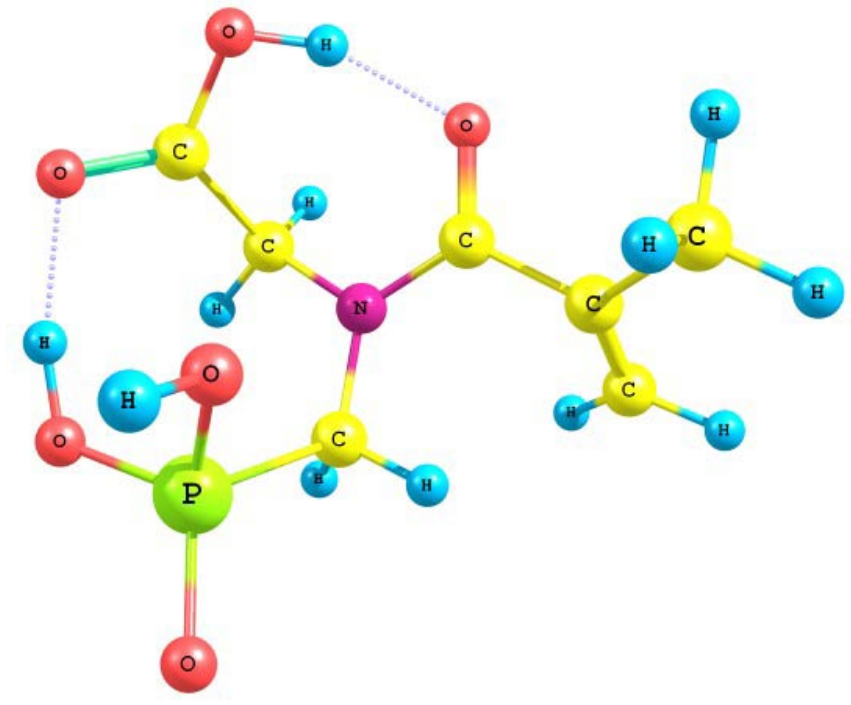

The sole exception we found to the $\pm 120^{\circ}$ rule was a structure at $+2.25 \mathrm{kcal} / \mathrm{mol}$, which had an acryloyl dihedral angle of $-39^{\circ}$. Its structure is shown here:

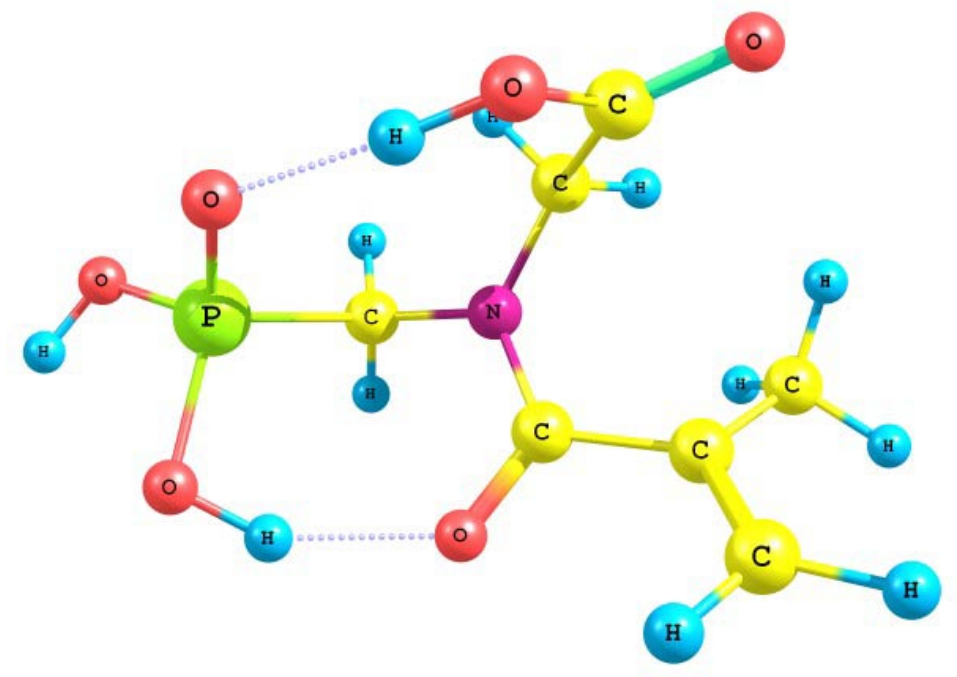

AA. Identified local minima showed a wider range of both energy and dihedral angle. As with MA, the "global" minimum had the phosphoryl group acting as a hydrogen-bond donor to the acryloyl carbonyl oxygen. However, optimized dihedral angles fell into two groups: $\pm 2^{\circ}$ (the lowest-energy structures) and $\pm 130^{\circ}$.

Structures in which the acryloyl group was essentially planar took on an s-cis conformation. Hydrogen-bonding from the carboxyl group rather than the phosphoryl group raised the energy by about $3.5 \mathrm{kcal} / \mathrm{mol}$. Representative structures are shown below: 

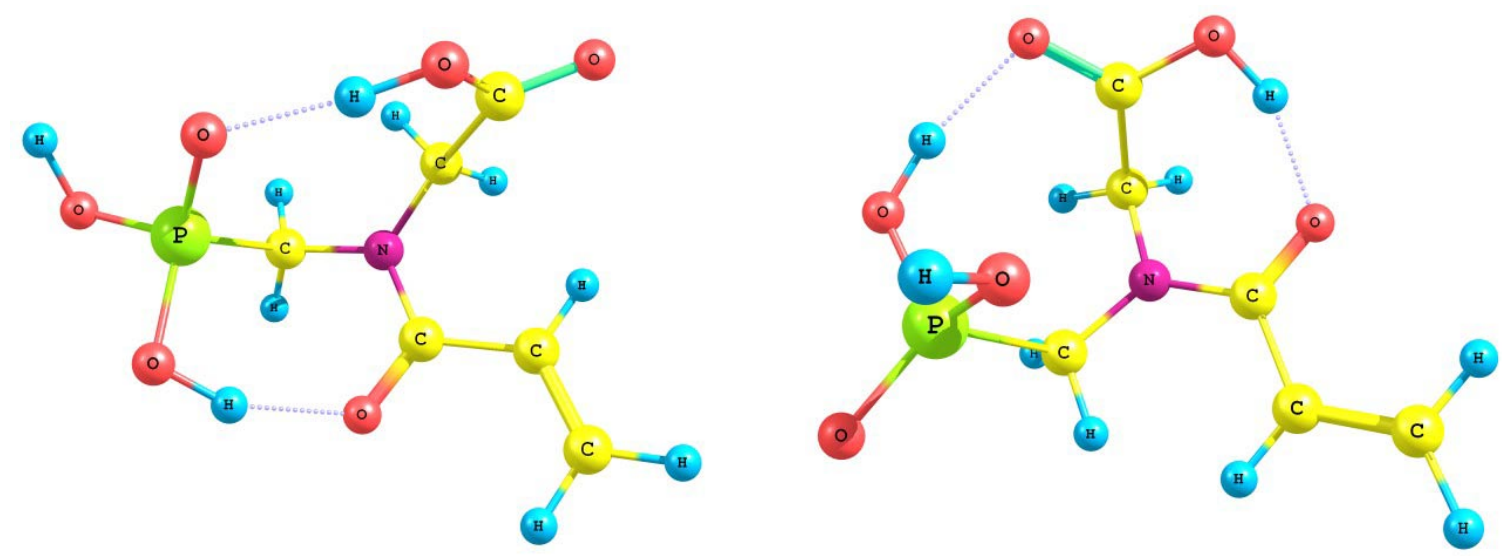

Structures in which the acryloyl group was twisted $\pm 130^{\circ}$ lay about $3.5 \mathrm{kcal} / \mathrm{mol}$ above the "global" minimum. Hydrogen-bonding from the carboxyl group rather than the phosphoryl group raised the energy about $2.5 \mathrm{kcal} / \mathrm{mol}$. Representative structrures are shown below:
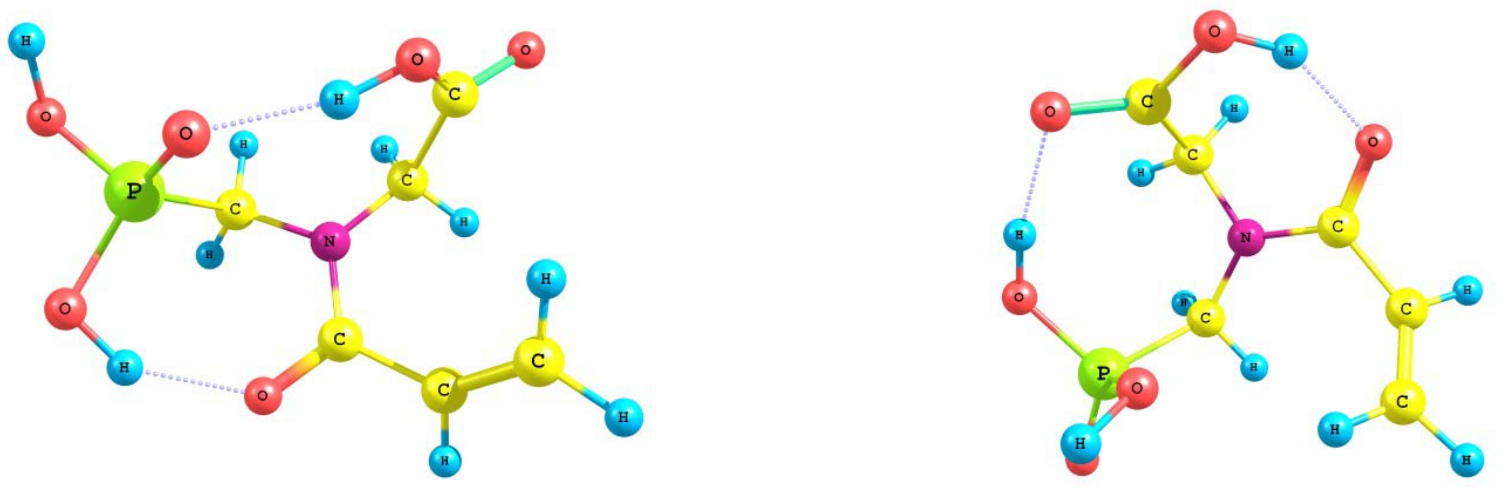

\section{References}

1. Spartan 04, Wavefunction, Inc., Irvine, CA 92612.

2. Gaussian 03, Revision C.02, Frisch, M. J.; Trucks, G. W.; Schlegel, H. B.; Scuseria, G. E.; Robb, M. A.; Cheeseman, J. R.; Montgomery, Jr., J. A.; Vreven, T.; Kudin, K. N.; Burant, J. C.; Millam, J. M.; Iyengar, S. S.; Tomasi, J.; Barone, V.; Mennucci, B.; Cossi, M.; Scalmani, G.; Rega, N.; Petersson, G. A.; Nakatsuji, H.; Hada, M.; Ehara, M.; Toyota, K.; Fukuda, R.; Hasegawa, J.; Ishida, M.; Nakajima, T.; Honda, Y.; Kitao, O.; Nakai, H.; Klene, M.; Li, X.; Knox, J. E.; Hratchian, H. P.; Cross, J. B.; Bakken, V.; Adamo, C.; Jaramillo, J.; Gomperts, R.; Stratmann, R. E.; Yazyev, O.; Austin, A. J.; Cammi, R.; Pomelli, C.; Ochterski, J. W.; Ayala, P. Y.; Morokuma, K.; Voth, G. A.; Salvador, P.; Dannenberg, J. J.; Zakrzewski, V. G.; Dapprich, S.; Daniels, A. D.; Strain, M. C.; Farkas, O.; Malick, D. K.; Rabuck, A. D.; Raghavachari, K.; Foresman, J. B.; Ortiz, J. V.; Cui, Q.; Baboul, A. G.; Clifford, S.; Cioslowski, J.; Stefanov, B. B.; Liu, G.; Liashenko, A.; Piskorz, P.; Komaromi, I.; Martin, R. L.; Fox, D. J.; Keith, T.; Al-Laham, M. A.; Peng, C. Y.; Nanayakkara, A.; Challacombe, M.; Gill, P. M. W.; Johnson, B.; Chen, W.; Wong, M. W.; Gonzalez, C.; and Pople, J. A.; Gaussian, Inc., Wallingford CT, 2004. 


\section{Molecular Mass Determination for Homopolymer of AA}

Molecular mass of the poly(acrylated glyphosate) was estimated by chromatography on an HPLC gel-exclusion column. Two asymmetric peaks corresponding to the highmolecular weight polymer and oligomer residues were observed. HPLC gel-filtration profile of homopolymer of acrylated glyphosate is presented on Figure S9. Molecular mass of the fraction corresponding to the elution time of 20-35 min was determined using calibration line as shown in Figure S10. The molecular weight of poly(acrylated glyphosate) lies in the range of $55 \pm 10 \mathrm{kDa}$.

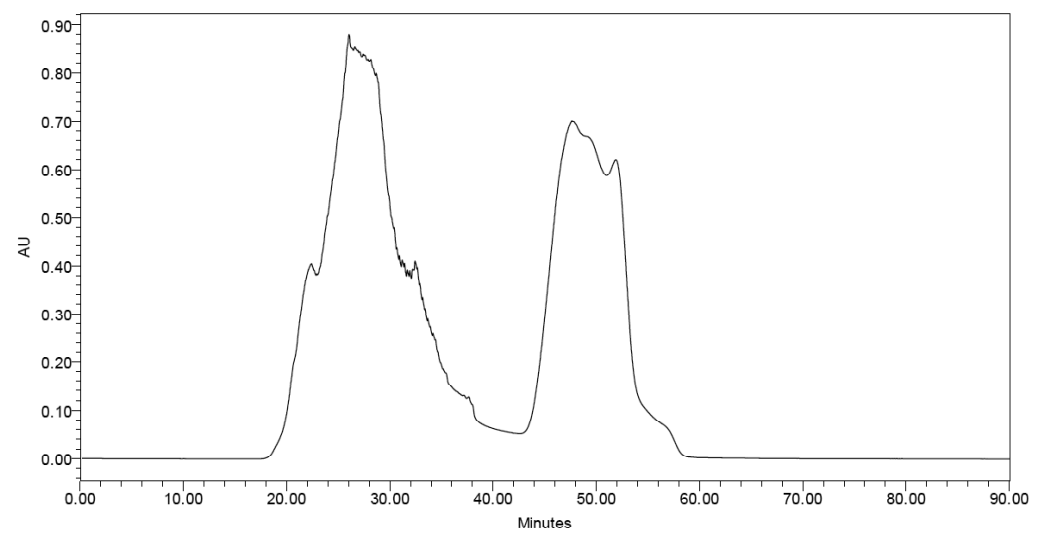

Figure S9. HPLC gel-filtration profile of poly(acrylated glyphosate)

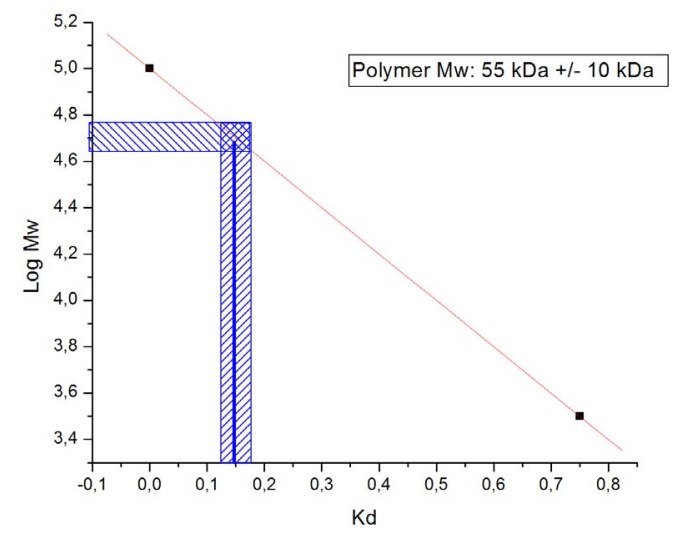

Figure S10. Calibration curve for molecular mass determination of poly(acrylated glyphosate).

All attempts to obtain the molecular weight of the resulting polymer using MALDI-TOF and ESI LC mass spectrometry were unsuccessful. 


\section{Compositions of Growth Media}

BG-11 Culture Medium.

Composition of BG-11 culture medium (per 1 L): $\mathrm{NaNO}_{3}$ 10ml $(15 \mathrm{~g} / 100 \mathrm{ml})$; $\mathrm{CaCl}_{2} * 2 \mathrm{H}_{2} \mathrm{O} 1 \mathrm{ml}$ (3.6g/100ml); FeNH ${ }_{4}$ Citrate $1 \mathrm{ml}$ (1.2g/100ml); $\mathrm{Na}_{2}$ EDTA $1 \mathrm{ml}$ $(0.1 \mathrm{~g} / 100 \mathrm{ml}) ; \mathrm{K}_{2} \mathrm{HPO}_{4} 1 \mathrm{ml}(4.0 \mathrm{~g} / 100 \mathrm{ml}) ; \mathrm{MgSO}_{4} 1 \mathrm{ml}(7.5 \mathrm{~g} / 100 \mathrm{ml}) ; \mathrm{Na}_{2} \mathrm{CO}_{3} 1 \mathrm{ml}$ (2.0/100ml); Micronutrients $1 \mathrm{ml}$ - Contain: $\mathrm{H}_{3} \mathrm{BO}_{3} 2.8 \mathrm{~g} / \mathrm{L}, \mathrm{MnCl}_{2} * 4 \mathrm{H} 2 \mathrm{O} 1.8 \mathrm{~g} / \mathrm{L}$, $\mathrm{ZnSO}_{4} * 7 \mathrm{H}_{2} \mathrm{O} 0.222 \mathrm{~g} / \mathrm{L}, \mathrm{Na}_{2} \mathrm{MoO}_{4} * 2 \mathrm{H}_{2} \mathrm{O} 0.39 \mathrm{~g} / \mathrm{L}, \mathrm{CuSO}_{4} * 5 \mathrm{H}_{2} \mathrm{O} 0.079 \mathrm{~g} / \mathrm{L}, \mathrm{CoCl}_{2} * 6 \mathrm{H}_{2} \mathrm{O}$ $0.012 \mathrm{~g} / \mathrm{L}$.

M9 Minimum Medium.

Composition of minimum M9 medium (per $1 \mathrm{~L}$ ): $20 \mathrm{ml}$ M9 salt (per $1 \mathrm{~L}: \mathrm{Na}_{2} \mathrm{HPO}_{4} 33.9 \mathrm{~g}$, $\mathrm{KH}_{2} \mathrm{PO}_{4} 15 \mathrm{~g}, \mathrm{NaCl} 2.5 \mathrm{~g}, \mathrm{NH}_{4} \mathrm{Cl} 5 \mathrm{~g}$ ), $1 \mathrm{M} \mathrm{MgSO}_{4} 2 \mathrm{ml} ; 20 \%$ glucose solution $20 \mathrm{ml} ; 1 \mathrm{M}$ $\mathrm{CaCl}_{2} 0.1 \mathrm{ml}$. 